\title{
Thickened tailings - a water and energy consumption perspective
}

J.H.L. Möller Paterson \& Cooke, South Africa

A.J.C. Paterson Paterson \& Cooke, South Africa

T. Verbeek Anglo American Kumba Iron Ore, South Africa

\section{Abstract}

A bench-scale thickening and rheology test campaign was conducted on iron ore tailings material originating from a pilot plant for a potential concentrates beneficiation project situated in the Northern Cape province of South Africa. The purpose of this study was to determine the optimum thickened target density for the slimes generated by the pilot plant by considering both water and energy consumption. A water and energy consumption model was developed to indicate at which thickened density the optimum water recovery and energy consumption cost benefit is obtained. The model indicates that for the pilot plant tailings material, water consumption is reduced by thickening up to an optimum density where after energy consumption increases exponentially and - considering the current ratio between the cost of water and the cost of electricity - the water consumption economic benefit is lost.

\section{Introduction}

In recent times the drive to incorporate paste and thickened tailings (P\&TT) technology in the process plant design has become less of a mine-driven attempt to cut raw water usage and reduce tailings storage facility (TSF) footprint, and more of a regulator-driven undertaking to ensure that mining operations comply with environmental legislation and high-level pressure regarding water usage in South Africa.

Consequently, huge leaps have been made in P\&TT technology in the last few years with the aim of producing high density tailings streams to recover high percentages of water at the process plant and to reduce the overall mine water consumption. The outcome is often a seemingly ideal water strategy that promises to have the mining operator saving money through a reduction in water consumption and the regulator content with the efficient water management methods.

The understanding that is often lacking in the industry is that P\&TT disposal revolves around more than high-density, high-compression and so called paste thickening. P\&TT disposal cannot be discussed without considering thickening, transport and deposition as a whole. When these components are not considered concurrently, a strategy aimed at improving "the way we do things" can become an unfortunate step back in P\&TT technology.

It is the purpose of this paper to demonstrate an instance where water and energy consumption was considered in parallel during the development of a tailings disposal strategy and to provide insight into the effect that these two factors have on each other.

\section{$2 \quad$ Methodology}

\section{1 Test programme}

For this study, tailings material was generated through thickening test work conducted on an iron ore tailings sample originating from a beneficiation pilot plant and thickened in a bench-top dynamic thickening rig. 
The measured material properties are given in Table 1.

Table 1 Material properties

\begin{tabular}{lc}
\hline Parameter & Value \\
\hline Solids density & $3,750 \mathrm{~kg} / \mathrm{m}^{3}$ \\
Particle size: & \\
$\mathrm{d}_{50}$, the mean particle size & $3.8 \mu \mathrm{m}$ \\
$\mathrm{d}_{90}$ & $31 \mu \mathrm{m}$ \\
Solids concentration by mass & $53-55 \% \mathrm{~m}$ \\
Slurry density & $1,640-1,680 \mathrm{~kg} / \mathrm{m}^{3}$ \\
\hline
\end{tabular}

Underflow material generated in a bench-top dynamic thickening rig underwent sedimentation tests in a $500 \mathrm{~cm}^{3}$ cylinder, in which the sample was allowed to settle under its own weight in an undrained condition. Thereafter, the water released above the consolidated mud bed was allowed to drain vertically under drained conditions.

Figure 1 provides a schematic diagram of the sequence of tests that were conducted.

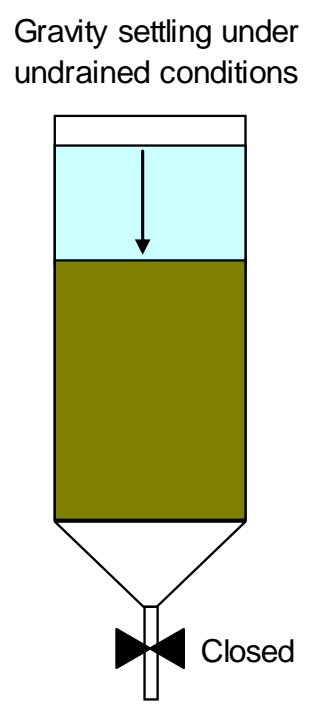

\section{Gravity settling under drained conditions}

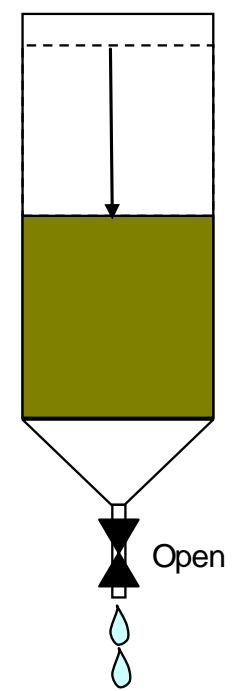

Figure 1 Undrained and drained consolidation tests

In addition, seven undrained consolidation tests were conducted at a range of solids concentrations between 26 and $51 \% \mathrm{~m}$ over a period of 12 weeks in order to determine the undrained water release over a solids concentration range, which is required in order to calculate the final water consumption figures.

Rotational viscometer tests were conducted on freshly thickened underflow to determine the relationship between solids concentration, yield stress and viscosity. Tests were conducted for a range of solids concentrations to determine the flow characteristics of the sample.

\section{2 Water consumption model background}

The water consumption model constructed for this study is based on a closed system analysis of the concentrate plant tailings stream. No other unit processes within the Sishen operation were considered and consumption figures reported in this study are solely based on the concentrate plant tailings thickener and thickened underflow stream. 
Figure 2 gives a graphical overview of the parameters taken into consideration for this study.

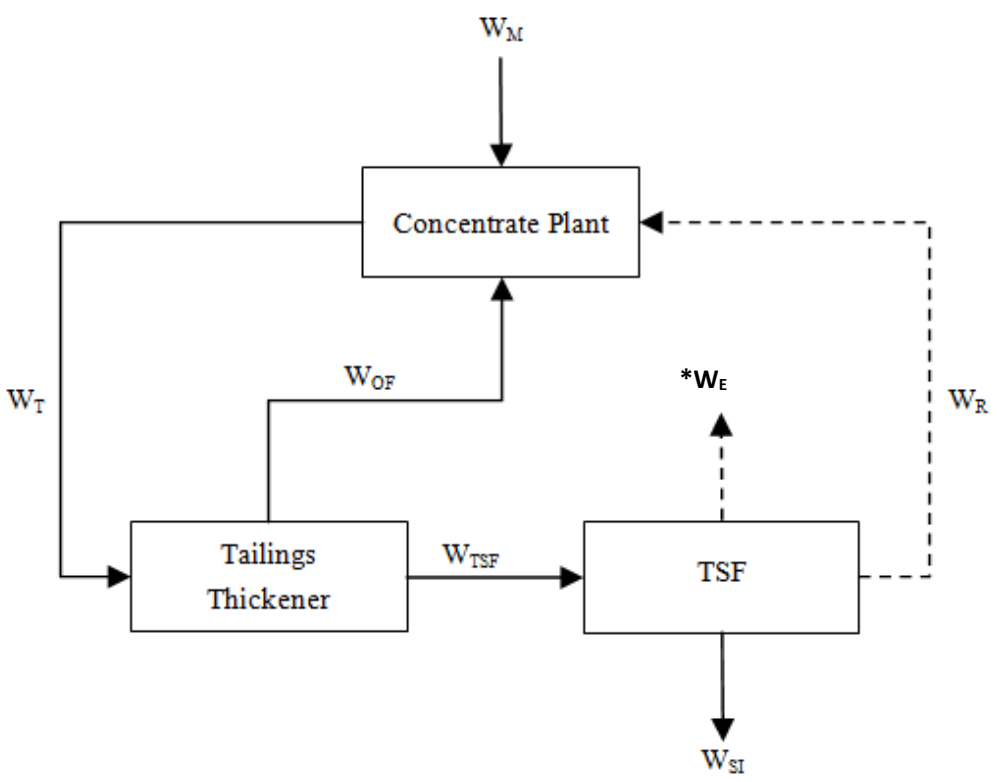

Figure 2 Water consumption model (Vietti et al., 2010)

The following parameters were considered:

- $\mathrm{W}_{\mathrm{M}}$, volumetric flow rate of water required to make-up water losses $\left(\mathrm{m}^{3} / \mathrm{h}\right)$.

- $W_{T}$, volumetric flow rate of water reporting to tailings thickener $\left(m^{3} / h\right)$.

- $\mathrm{W}_{\mathrm{OF}}$, volumetric flow rate of water recovered from tailings thickener $\left(\mathrm{m}^{3} / \mathrm{h}\right)$.

- $\mathrm{W}_{\text {TSF, }}$ volumetric flow rate of water reporting to $\operatorname{TSF}\left(\mathrm{m}^{3} / \mathrm{h}\right)$.

- $\mathrm{W}_{\mathrm{sl}}$, volumetric flow rate of water lost to seepage and interstitial water $\left(\mathrm{m}^{3} / \mathrm{h}\right)$.

- $W_{R}$, volumetric flow rate of water released from TSF $\left(m^{3} / h\right)$.

- ${ }^{*} W_{E}$, volumetric flow rate of water lost as evaporative losses $\left(m^{3} / h\right)$.

For the purpose of this study, water losses at the TSF relating to evaporative losses at the wet and dry beach, pond and return water dam, as well as seasonal water losses/gains relating to climatic variables were not taken into consideration.

In order to account for such variables a detailed geotechnical water balance must be completed over the TSF which was not included in this study. Furthermore, it is exceedingly problematic to conduct such an analysis for a closed system due to other unit processes within the plant affecting the model parameters of the TSF.

Consequently, parameter $W_{R}$ which defines the water returned from the TSF to the plant is estimated as the total amount of water released at the TSF, without deducting losses for the abovementioned variables.

The parameters in Table 2 were fixed as input parameters for the water consumption desktop study. 
Table 2 Input parameters

\begin{tabular}{lc}
\hline Parameter & Value \\
\hline Concentrate tailings thickener dry tonnage (maximum) & $212.6 \mathrm{t} / \mathrm{h}$ \\
Thickener feed solids concentration & $11.2 \% \mathrm{~m}$ \\
Thickener feed slurry flow rate & $1,748.5 \mathrm{~m}^{3} / \mathrm{h}$ \\
Water reporting to tailings thickener (WT) & $1,691.9 \mathrm{~m}^{3} / \mathrm{h}$ \\
\hline
\end{tabular}

\section{3 Pumping desktop study process conditions}

This high-level study considered the basic layout shown in Figure 3, pumping thickened tailings $5 \mathrm{~km}$ from the process plant to the tailings storage facility.

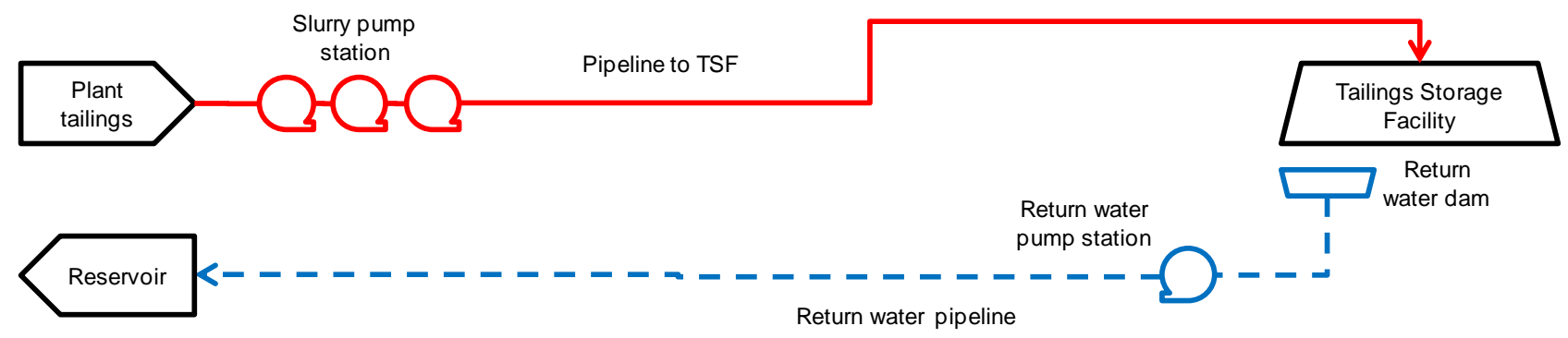

Figure 3 Schematic layout of pumping system

- Slurry system:

- Distance from pump station to tailings facility: $5 \mathrm{~km}$

- Static lift to top of facility: $+25 \mathrm{~m}$

- Return water:

- Distance from return water dam to process plant: $5 \mathrm{~km}$

- Static lift from return water dam to process plant reservoir: $+15 \mathrm{~m}$.

\section{1 Undrained consolidation}

The undrained consolidation curves for the continually consolidating underflow material, at a range of placed solids concentrations, are provided in Figure 4. 


\section{Undrained Consolidation Curves}

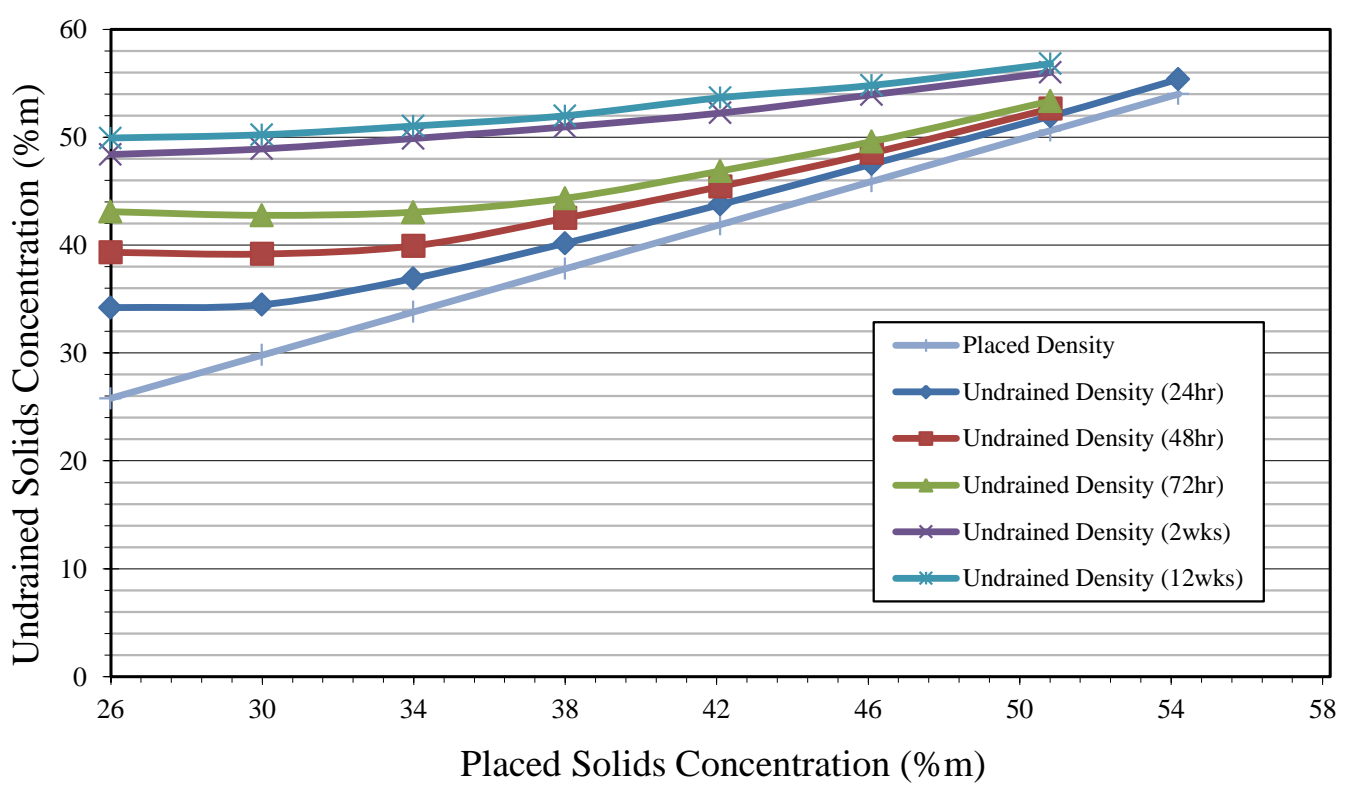

Figure 4 Undrained consolidation curves

These curves represent the consolidation of the undrained mud bed from a placed solids concentration to a final undrained solids concentration after a period of 12 weeks. The importance of these curves is that over the range of initial solids concentrations $(26-54 \% \mathrm{~m})$ the final undrained solids concentrations are not uniform, i.e. the material does not consolidate to the same undrained solids concentration irrespective of the starting solids concentration.

This contradicts the widely accepted view that a slurry will consolidate to a uniform density, irrespective of the density at which it is placed. This view however does not differentiate between drained and undrained consolidation and does not specify which prevails at the TSF.

The undrained water release represents the total amount of water released as supernatant from the consolidating mud bed at the TSF and furthermore, the maximum amount of water recoverable at the TSF within timeframes considered metallurgically important. The remaining water within the mud bed can only be subjected to drainage/seepage losses or will remain in the bed as interstitial water.

Consequently, the undrained water release curve provides valuable information such as the placed solids concentration of $62 \% \mathrm{~m}$ where no bleed water is released from the deposited material, as shown in Figure 5. 
Undrained Consolidation Model

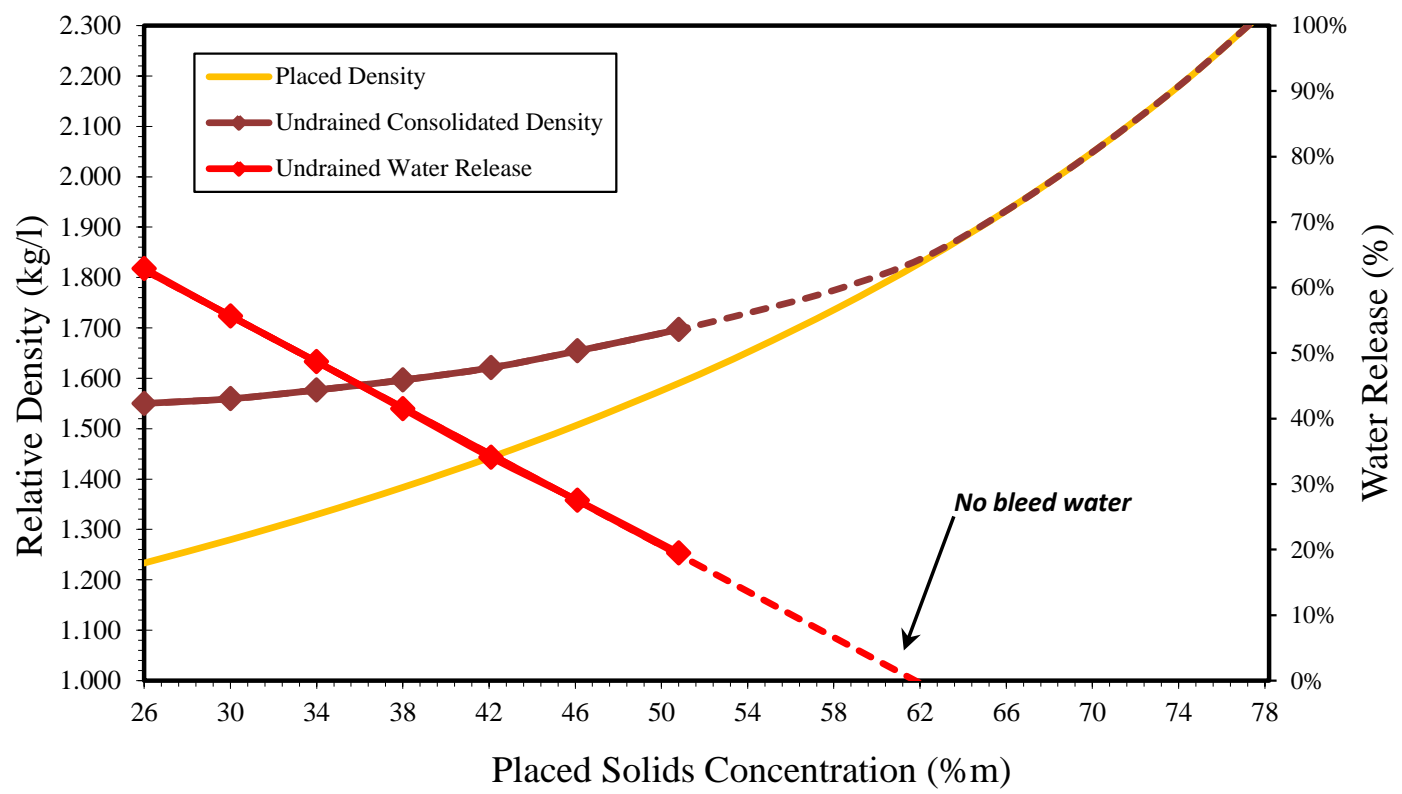

Figure 5 Undrained consolidation model

As seen, the undrained water release data points form a linear correlation with the placed solids concentration and an extrapolation of this line results in an intersect on the $\mathrm{x}$-axis at $62 \% \mathrm{~m}$ - where the water release equals $0 \%$. At higher solids concentrations the water release remains $0 \%$ meaning that no further bleed water is released beyond this density.

The drained water release, on the other hand, represents the total amount of water released as supernatant from the consolidating mud bed, as well as drainage/seepage water released through the base of the TSF. Barring environmental parameters, which are not considered in this study, the inverse of the drained water release would represent the amount of water contained in the consolidated mud bed as interstitial water, which can neither be recovered as supernatant, nor be lost through drainage/seepage.

Based on the closed system analysis and constraints provided in section 2.2, as well as the undrained water release data calculated from the consolidation test work, the water balance and consumption figures can be determined using a water consumption model.

\section{2 Water consumption model}

The fundamental parameter in the water consumption model is $W_{M}$, or the volumetric flow rate of makeup water required to account for water loss. This parameter is defined by the following equation:

$$
\mathrm{W}_{\mathrm{M}}=\mathrm{W}_{\mathrm{T}}-\mathrm{W}_{\mathrm{OF}}-\mathrm{W}_{\mathrm{R}}
$$

where:

$\mathrm{W}_{\mathrm{T}}=$ the amount of water reporting to the tailings thickener.

$\mathrm{W}_{\mathrm{OF}}=$ the amount of water recovered in the thickener overflow.

$\mathrm{W}_{\mathrm{R}}=$ the amount of water recovered in the return water line from the TSF.

For a range of thickened densities, $W_{T}$ and $W_{O F}$ are easily determined, but $W_{R}$ depends on the water release characteristics of the material. As explained previously, $W_{R}$ is calculated from the undrained water release data calculated from the consolidation test work.

Completing the water balance over a range of densities allows for the calculation of the target parameter, $\mathrm{W}_{\mathrm{M}}$, or the volumetric flow rate of make-up water required to account for the water loss. This parameter 
gives the basic water consumption as the amount of water consumed in $\mathrm{m}^{3}$ per tonne of dry material placed at the TSF and is solely based on the maximum undrained water release data generated through test work and no evaporative losses or seasonal water losses/gains relating to climatic variables are taken into consideration.

It is expected that under actual conditions, this parameter $\left(W_{M}\right)$ will be significantly affected by the environmental losses mentioned above.

Barring these environmental losses and considering only the water losses due to the consolidation and water retention behaviour of the underflow at different placed densities, the water consumption model derived for this material is given in Figure 6.

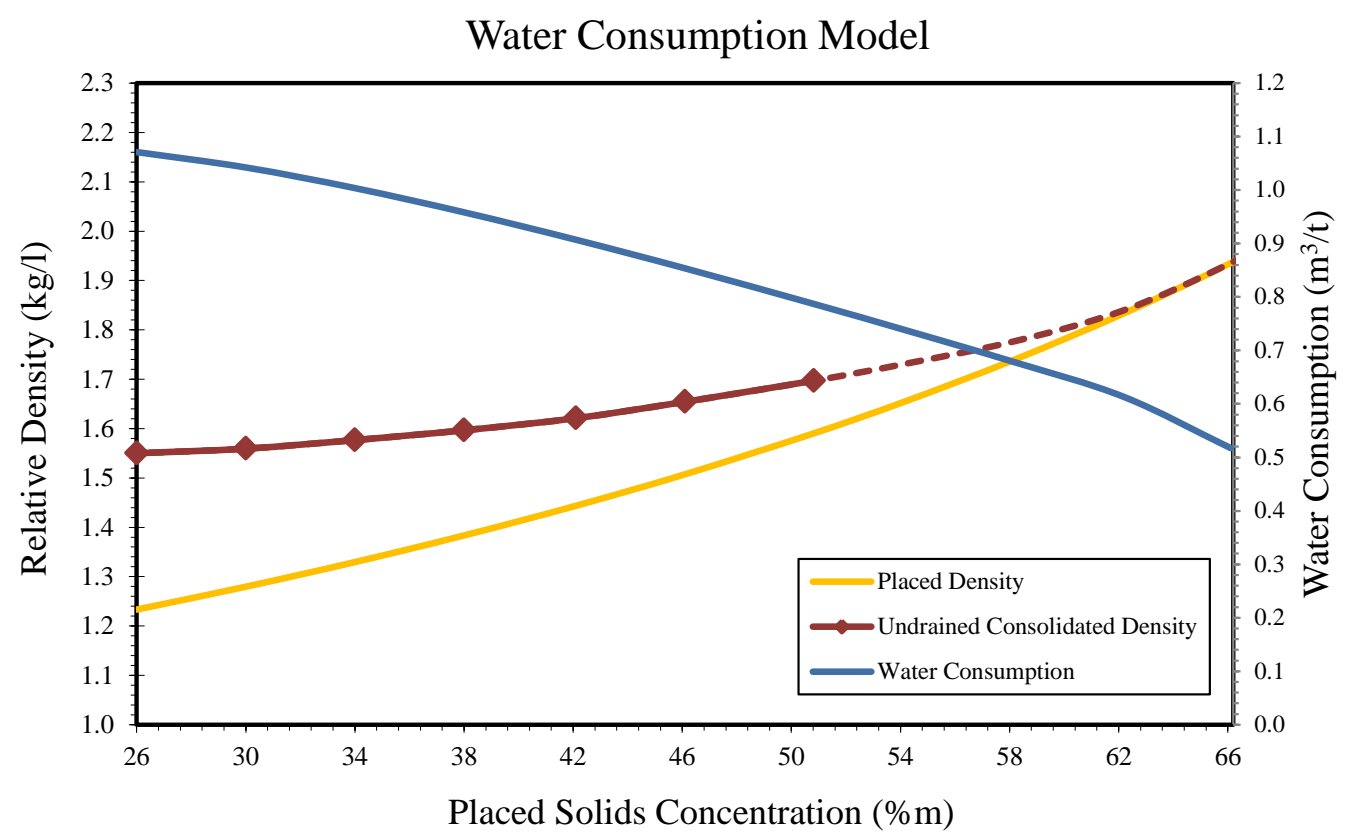

Figure 6 Water consumption model

A $29 \%$ reduction in water usage is realised when increasing the placed density of this flocculated, thickened material from a placed solids concentration of $30 \% \mathrm{~m}$ - where the water consumption is approximately $1.04 \mathrm{~m}^{3}$ per tonne of material placed at the TSF - to a placed solids concentration of $54 \% \mathrm{~m}$ where the water consumption is approximately $0.74 \mathrm{~m}^{3}$ per tonne of material placed at the TSF.

From the water consumption curve it is evident that the water savings benefit increases as the placed solids concentration increases.

\section{3 Rheology analysis}

The viscous properties used for this study are given in Figure 7. The plastic viscosity and yield stress increase steeply above solids concentrations of $50 \% \mathrm{~m}$, and this has a substantial impact on the pumping requirements, as demonstrated in the following section. 


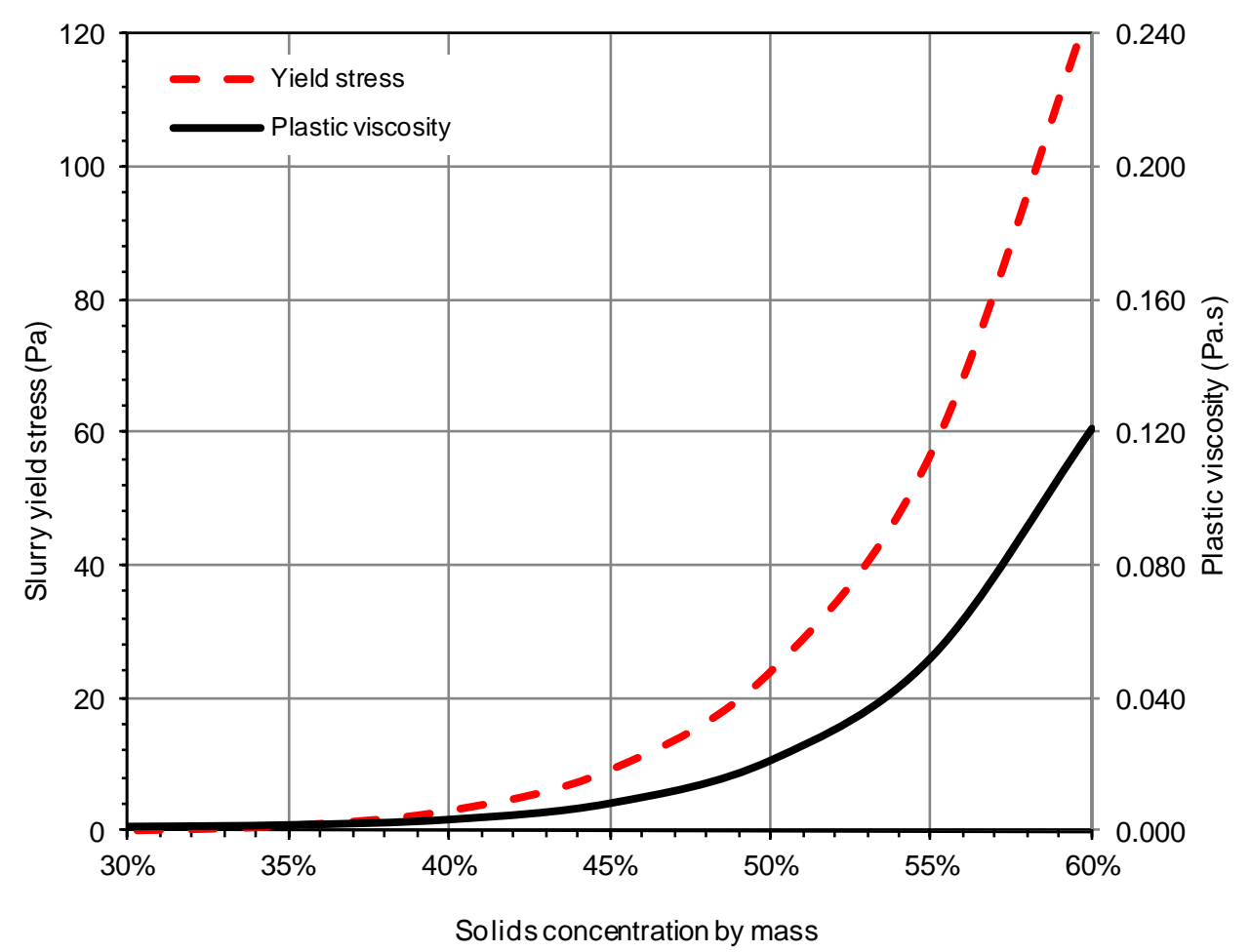

Figure 7 Yield stress and plastic viscosity versus solids concentration

\section{4 Energy consumption model}

The energy consumption model is based on a solids concentration range of $30-60 \% \mathrm{~m}$ with various design criteria taken into consideration:

- Pipeline diameter: slurry velocity, viscosity and pressure gradient as well as the commercial availability of the selected pipeline diameter.

- High-pressure centrifugal pumps versus high pressure positive displacement pumps to satisfy discharge pressure requirements.

- Return water transport.

\section{5 Hydraulic design}

The pipeline diameter selection is based on meeting the following criteria to prevent deposition on the pipeline invert:

- At low solids concentrations (low viscosity) the slurry velocity must be greater than the solids deposition velocity.

- As viscosity increases the flow regime changes from turbulent to laminar at low velocities, and the operating velocity should be in turbulent flow. This is to prevent laminar flow settling, or stratified laminar flow, that results in a bed of coarse particles depositing on the pipe invert.

- When the slurry is very viscous it is not possible to operate in turbulent flow as the velocities will be excessive. In this case the pipe diameter must be selected so that there is at least a pressure loss of $1.5-2 \mathrm{kPa} / \mathrm{m}$ that is sufficient to move a settled bed of particles.

Figure 8 shows the selection of diameter based on commercially available steel pipelines. It is not always possible to meet all the above criteria, and in such cases the pipeline may operate with a stationary bed. 
The following is seen:

- At 30 and 35\%m - piping with an internal diameter of $304 \mathrm{~mm}$ is selected. The operating velocity is greater than the deposit velocity and the flow is turbulent, as the velocity is also greater than the laminar to turbulent transition.

- At $40 \% \mathrm{~m}$ - piping with an internal diameter of $253 \mathrm{~mm}$ is selected as the flow rate is reduced. There is still a margin between the operating velocity and the deposit velocity that has decreased due to the increased viscosity, and the flow remains turbulent, as the velocity is also greater than the laminar to turbulent transition.

- At $45 \% \mathrm{~m}$ - piping with an internal diameter of $253 \mathrm{~mm}$ is used, however, at the operating velocity the flow will be laminar. Using a smaller pipeline is not practical for these flow rates as the velocities increase substantially. The pipeline will operate with a partially settled bed of solids when the material is viscous, and any decrease in density or viscosity will likely re-suspend the solids.

- At $50 \% \mathrm{~m}$ - piping with an internal diameter of $199 \mathrm{~mm}$ is used to maintain velocities so as to be as close to the laminar to turbulent transition as possible, and there is likely to be a settled bed of solids on the pipe invert under laminar flow conditions.

- At $55 \% m-$ As this material is now very viscous, the pressure gradient is sufficiently high to ensure that any settled solids are removed from the pipeline, and it is safe to operate in laminar flow in a $199 \mathrm{~mm}$ internal diameter pipeline.

- At $60 \% \mathrm{~m}$ - This very viscous material has very high-pressure gradients and in order to reduce this, the pipe diameter is increased to $243 \mathrm{~mm}$ to reduce operating pressures. The pressure gradients are sufficiently high to ensure any deposited solids will slide on the pipe invert.

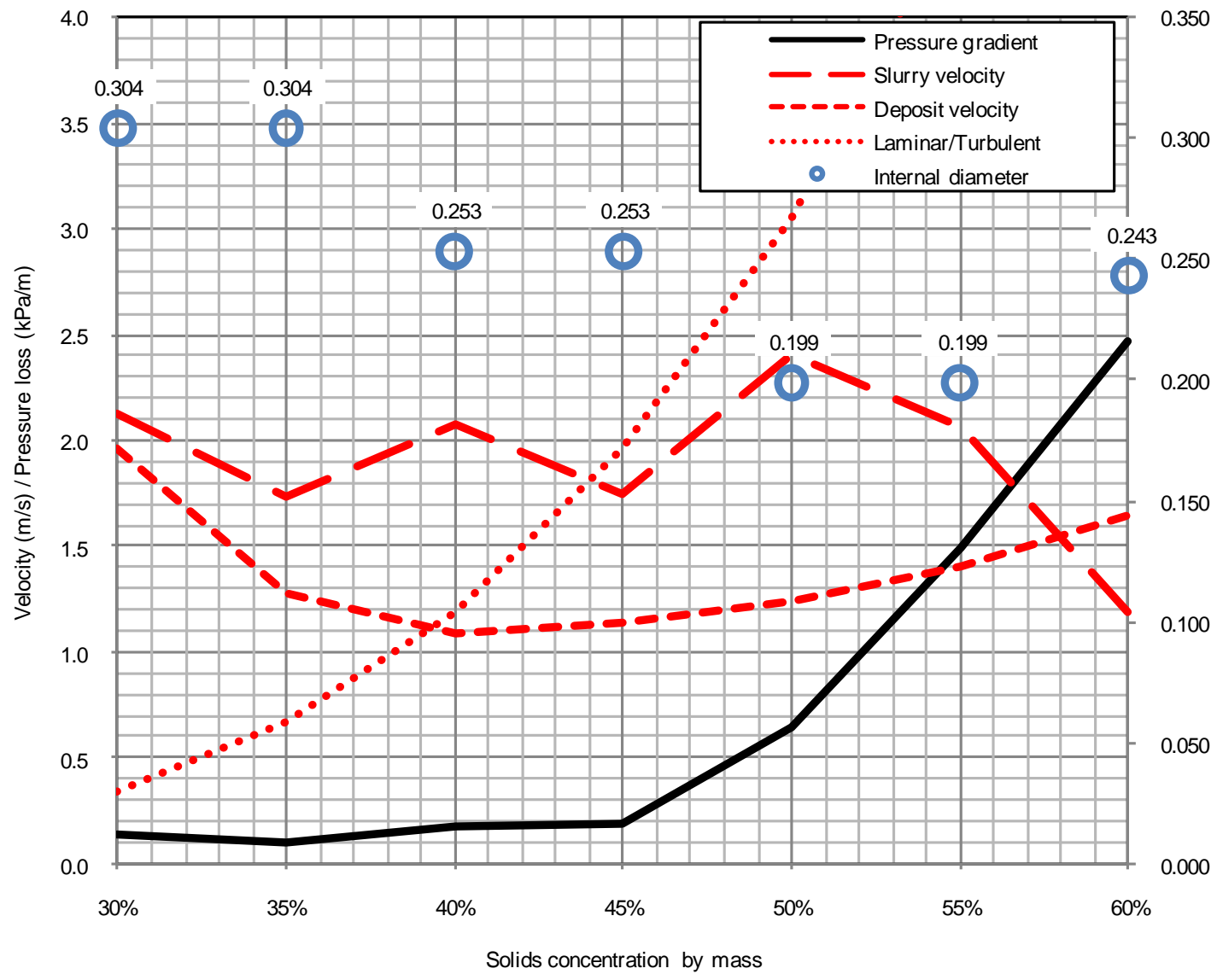

Figure 8 Pipeline selection and deposit velocity 


\section{6 Pumping requirements}

The pipeline system curves for each of the systems are shown in Figure 9 . Above 50\%m the pump station discharge pressure is beyond the typical capacity of high-pressure centrifugal pump casings, and highpressure positive displacement pumps are specified. Booster pump stations installed along the route are not practical at $60 \% \mathrm{~m}$, pump stations with multiple pumps in series would be needed approximately every $1.6 \mathrm{~km}$.

As the water release decreases at higher solids concentrations the pump and pipeline requirements of the return water system require small diameter pipelines that are not practical. For solids concentrations greater than $50 \% \mathrm{~m}$, the water pump and pipeline selection is the same, however the utilisation will decrease at higher solids concentrations.

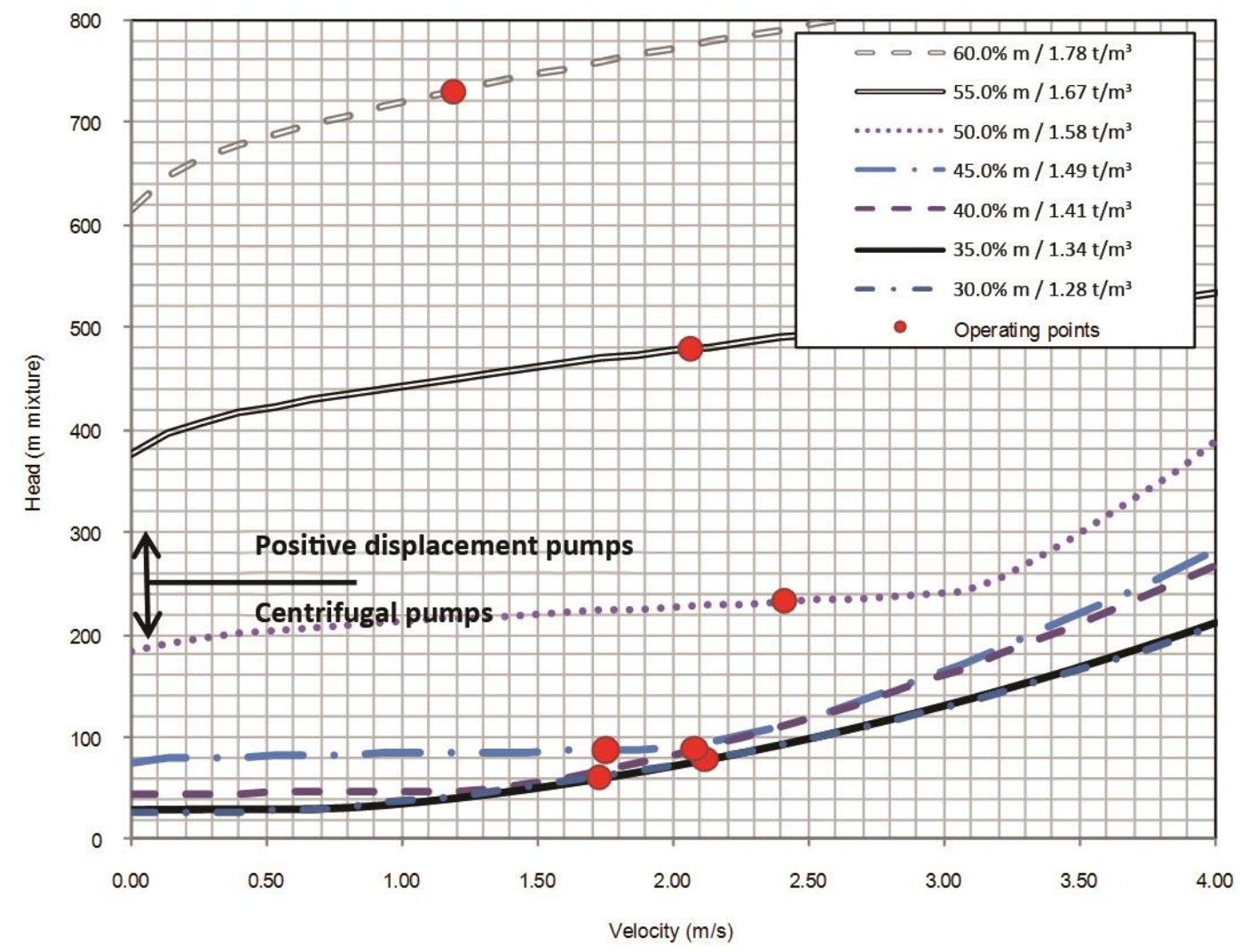

Figure 9 Pipeline system curves as solids concentration varies

The pumping duty is used to determine the absorbed power requirements, and the installed and absorbed power for each system is given in Figure 10, as well as the absorbed power per tonne dry solids per kilometre. The installed power includes $100 \%$ standby pumps for the slurry pumps, gland seal water pumps and return water pumps.

It can be seen that the optimum solids concentrations with regards to energy consumption lie between 35 and $45 \% \mathrm{~m}$. 


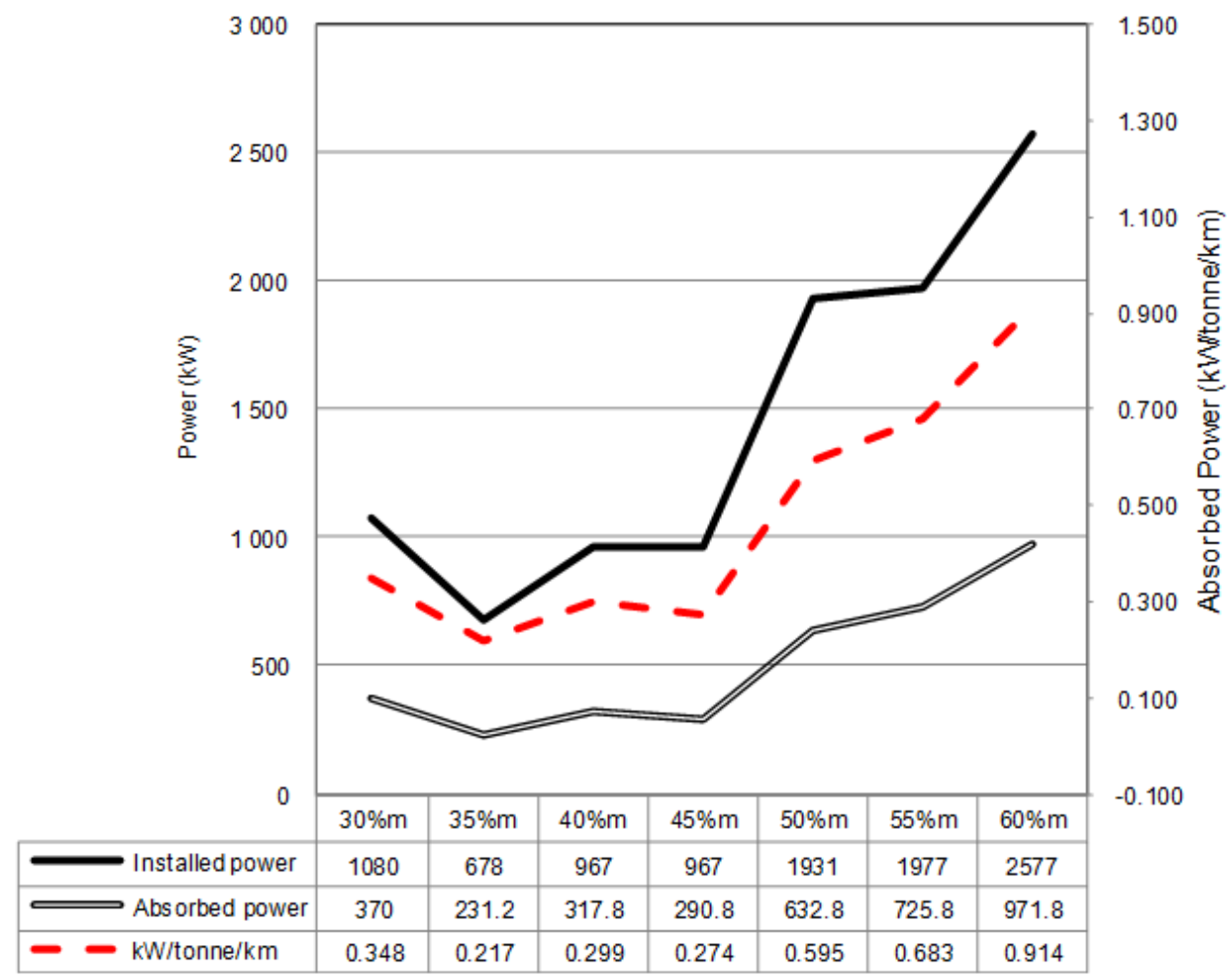

Figure 10 Power requirements

\section{Conclusions}

Combining the outcomes of the water consumption model with the calculated power requirements, a single water and energy consumption model was constructed to compare tailings placed density with water consumption $\left(\mathrm{m}^{3} / \mathrm{t}\right)$ and energy consumption $(\mathrm{kW} / \mathrm{t})$. Figure 11 provides the combined water and energy consumption model derived for the iron ore tailings material.

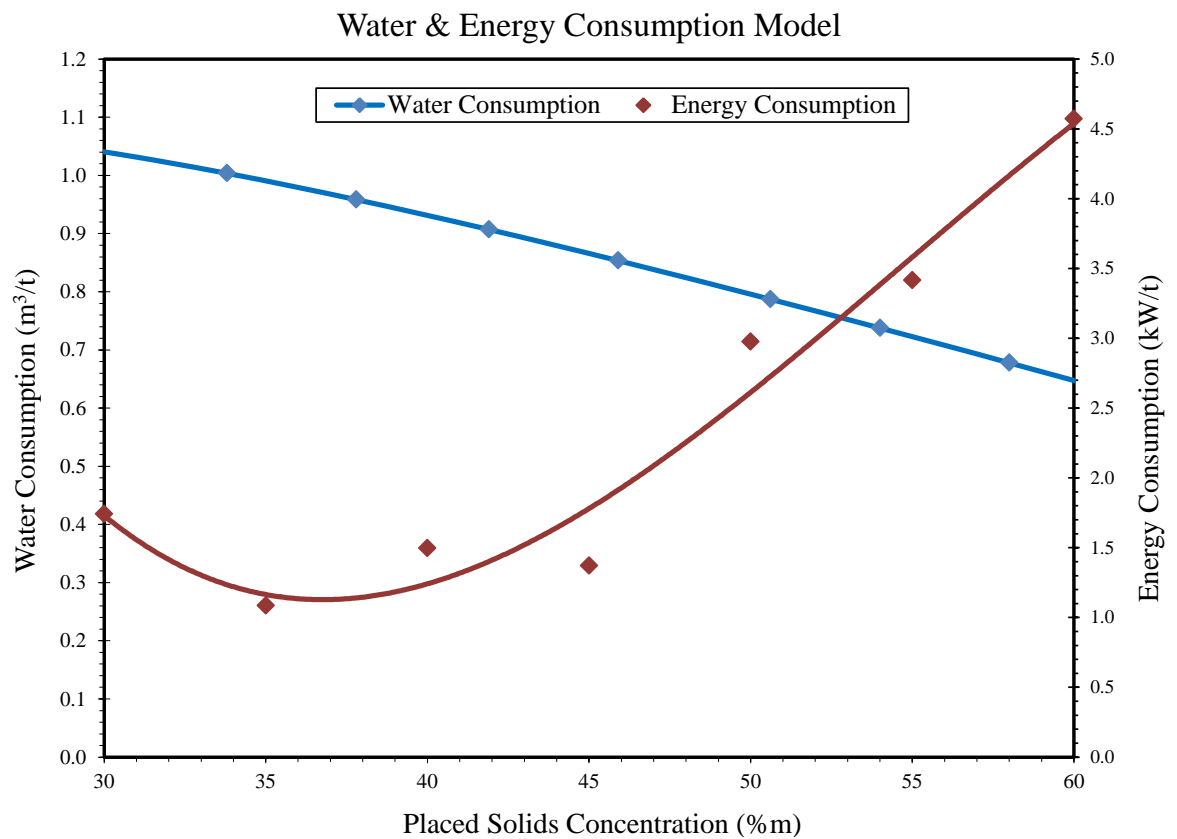

Figure 11 Combined water and energy consumption model

From a water consumption perspective, the water consumption benefit increases as the placed solids concentration increases. In simple terms, more water is recovered at the process plant with less water 
transported to the TSF, which is subjected to interstitial and drainage/seepage losses (without considering evaporative losses).

When considering only the water consumption aspect of the model, it can be said that the highest possible benefit is obtained when thickening to the highest possible underflow density.

However, when considering the energy consumption model it is clear that the energy consumption benefit is only obtained at placed solids concentrations between $35-45 \% \mathrm{~m}$, which results in the lowest overall power consumption and consequently, lowest operating cost per tonne. Furthermore it was determined that at solids concentrations greater than $50 \% \mathrm{~m}$ the capital costs increase due to the higher pump discharge pressures that require high pressure pumps and pipelines. Positive displacement pumps are needed at 55 and $60 \% \mathrm{~m}$.

This rheological behaviour is a unique characteristic of the specific material under investigation and cannot be correlated to other materials without conducting test work.

Ultimately a decision was made that for this particular material, and for the specific process conditions considered in this study, an optimum thickened target solids concentration of $45 \% \mathrm{~m}$ would provide the highest benefit when considering both water and energy consumption. In this particular instance it was determined that to economically increase the target solids concentration to a hypothetical value of $50 \% \mathrm{~m}$, the ratio between the cost of water (in $\mathrm{R} / \mathrm{m}^{3}$ ) and the cost of electricity (in $\mathrm{R} / \mathrm{kW}$ ) must increase from 4:1 (as used in this study) to a ratio of 10:1 - a 150\% increase in the raw water cost.

As discussed in the opening sections of this paper, it is imperative that a study of this nature also include aspects affecting water and energy consumption from a tailings deposition and storage perspective. This paper, however, came into existence because of an existing test campaign dealing with only tailings thickening and transport aspects. The geotechnical input necessary to complete a detailed all-round study was therefore not present at the time of this investigation, but remains a critical factor in considering the P\&TT disposal strategy.

The results of this study suggest that when conducting a water balance over the TSF to include evaporative losses into the water consumption model, the effect would be an exponential decrease in water recovery (and consequently an increase in water consumption) at lower placed densities due to larger pond and beach areas - unless the TSF is effectively managed to minimise this effect.

In conclusion, it is seen that although the drive for reducing overall plant water consumption is wellintentioned, there is more to the equation than simply investigating and employing a P\&TT disposal strategy through the acquisition of high-density, high-compression and so called paste thickeners.

Whilst this route may certainly reduce water consumption, the effect on energy consumption could be detrimental, resulting in a power, capital expense and operational expense intensive slurry transport system which effectively negates the water consumption cost benefit. This could result in a P\&TT disposal strategy that fulfils its function of reducing raw water costs, but essentially tips the scale towards a negative impact on the mining operator's energy consumption costs. Therefore, it is necessary to conduct a trade-off study to determine at which target density the highest overall economic benefit is obtained between the reduction in raw water and energy consumption.

\section{Acknow ledgements}

The authors wish to thank Anglo American Kumba Iron Ore for collaborating with Paterson \& Cooke in this study and for providing permission to publish this paper.

\section{References}

Vietti, A.J., Boshoff, J.C.J. and Cope, A. (2010) Does thickening save water?, in Proceedings Fourth International Platinum Conference Platinum In Transition 'Boom or Bust' 2010, 11-14 October, Sun City, South Africa, The Southern African Institute of Mining and Metallurgy, Johannesburg, Symposium Series S63, pp. 7-11. 